\title{
Synthesis of Poly(N-vinylcaprolactam)-Grafted Magnetite Nanocomposites for Magnetic Hyperthermia
}

\author{
A. Morfin-Gutiérrez $\mathbb{D}^{1}{ }^{1}$ H. Iván Meléndez-Ortiz, ${ }^{2}$ B. A. Puente-Urbina, ${ }^{1}$ \\ and L. A. García-Cerda iD ${ }^{1}$ \\ ${ }^{1}$ Centro de Investigación en Química Aplicada, Departamento de Materiales Avanzados, Blvd. Enrique Reyna Hermosillo \#140, \\ C.P. 25294 Saltillo, Coahuila, Mexico \\ ${ }^{2}$ CONACyT-Centro de Investigación en Química Aplicada, Blvd. Enrique Reyna Hermosillo \#140, CP 25294, Saltillo, \\ Coahuila, Mexico
}

Correspondence should be addressed to A. Morfin-Gutiérrez; adrianamorgut@gmail.com and L. A. García-Cerda; luis.garcia@ciqa.edu.mx

Received 16 June 2018; Revised 21 August 2018; Accepted 5 September 2018; Published 17 October 2018

Academic Editor: Jean M. Greneche

Copyright (C) 2018 A. Morfin-Gutiérrez et al. This is an open access article distributed under the Creative Commons Attribution License, which permits unrestricted use, distribution, and reproduction in any medium, provided the original work is properly cited.

\begin{abstract}
In this study, the synthesis, characterization, and application of poly( $\mathrm{N}$-vinylcaprolactam)-grafted magnetite nanocomposites for magnetic hyperthermia are reported. Superparamagnetic magnetite nanoparticles (MagNPs) with sizes in the range of 10-16 nm were synthesized by the coprecipitation method and then functionalized with vinyltrimethoxysilane (VTMS). MagNPs-VTMS coated with poly(N-vinylcaprolactam) (PNVCL) were prepared by free radical polymerization. The obtained materials were characterized by X-ray diffraction (XRD), transmission electron microscopy (TEM), vibration sample magnetometry (VSM), and Fourier transform infrared spectroscopy (FT-IR). The heating ability was evaluated under a magnetic field using a solid state induction heating equipment at $10.2 \mathrm{kA} / \mathrm{m}$ and $362 \mathrm{kHz}$. The MagNPs-PNVCL nanocomposites showed a behavior close to superparamagnetic materials, which is appropriated for magnetic hyperthermia treatment; in concentrations of $8 \mathrm{mg} / \mathrm{mL}$, they were able to heat up, increasing the temperature up to $42^{\circ} \mathrm{C}$ in a period of time lower than 10 minutes.
\end{abstract}

\section{Introduction}

Currently, magnetic nanoparticles coated with smart polymers have been attracting great attention due to their diverse applications in different fields, such as biotechnology and medicine. Magnetic particles are used by their capacity for dissociating in iron and elemental oxygen, which are subsequently consumed by the metabolic system [1]. In particular, bare magnetic particles have been used in magnetic resonance images and magnetic hyperthermia for cancer treatment, while hybrid systems (magnetic particles-smart polymer) have been mainly used as drug delivery systems [2]. The smart polymers have the ability to modify their physical properties in response to external stimuli, such as $\mathrm{pH}$, temperature, and ionic strength. Poly(N-vinylcaprolactam) (PNVCL) is a temperature-responsive polymer which exhibits changes in its properties at temperatures closed to the human body [3]. Magnetic particles-smart polymer nanocomposites offer the advantage not only to respond to an external magnetic field which is used to guide nanocomposites to a specific site but also to environmental external stimuli such as temperature and $\mathrm{pH}$ for inducing a controlled drug delivery.

In this research, a nanocomposite based on magnetite nanoparticles (MagNPs) and PNVCL was synthesized by free radical polymerization for its use in magnetic hyperthermia [4]. First, MagNPs were synthesized by a coprecipitation method and then covalently modified using a silane coupling agent (vinyltrimethoxysilane, VTMS), which contains a vinyl group, useful for the free radical polymerization of N-vinylcaprolactam. The structure, magnetic properties, and heat generation rate of the obtained materials were investigated. 


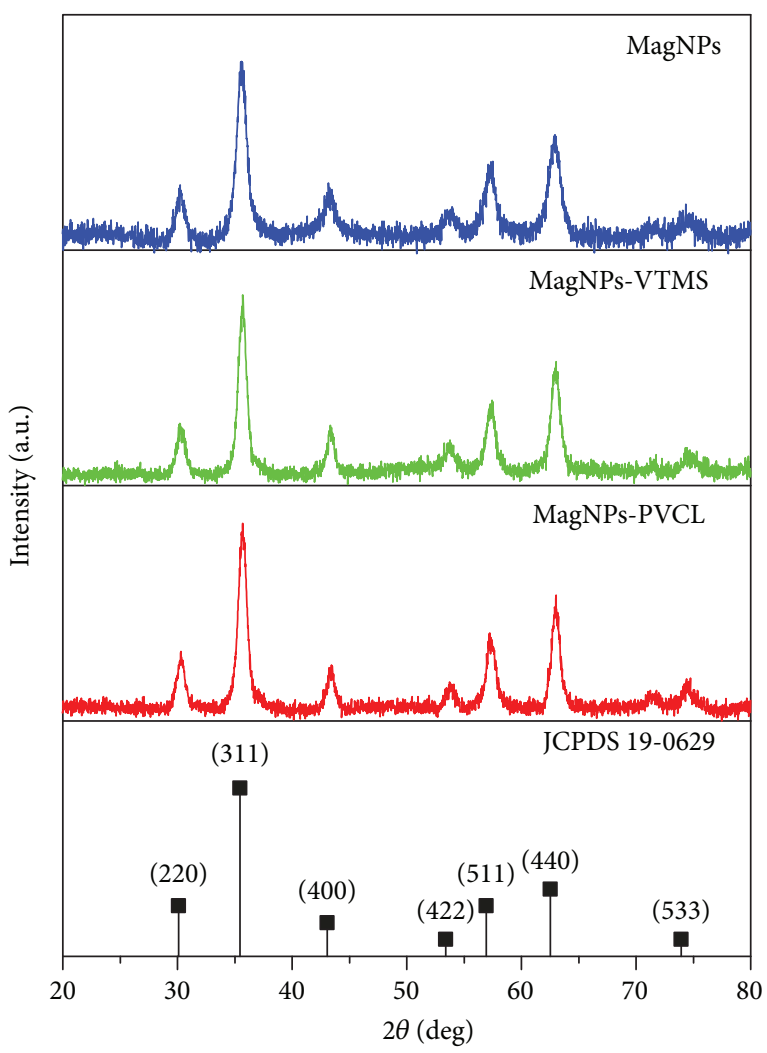

Figure 1: X-ray diffraction patterns of MagNPs, MagNPs-VTMS, and MagNPs-PNVCL nanocomposite.

\section{Experimental Details}

2.1. Materials. All reagents were used as received. Ferric chloride $\left(\mathrm{FeCl}_{3}{ }_{6} \mathrm{H}_{2} \mathrm{O}\right)$, ferrous chloride $\left(\mathrm{FeCl}_{2} \cdot 4 \mathrm{H}_{2} \mathrm{O}\right)$, ammonium hydroxide $\left(\mathrm{NH}_{4} \mathrm{OH}\right)$, vinyltrimethoxysilane $\left(\mathrm{H}_{2} \mathrm{C}=\mathrm{CHSi}\left(\mathrm{OCH}_{3}\right)_{3}\right)$, N-vinylcaprolactam $\left(\mathrm{C}_{8} \mathrm{H}_{13} \mathrm{NO}\right)$, and ammonium persulfate $\left(\left(\mathrm{NH}_{4}\right)_{2} \mathrm{~S}_{2} \mathrm{O}_{8}\right)$ were obtained from Aldrich. Water used in the experiments was deionized and filtered (Milli-Q water system).

2.2. Preparation of Magnetite Nanoparticles (MagNPs). MagNPs were synthesized by a coprecipitation method as follows. A ferric chloride solution was mixed with a ferrous chloride solution in a molar ratio $2: 1$. The solution was stirred at $2000 \mathrm{rpm}$ and heated at $70^{\circ} \mathrm{C}$. Then, the stirring rate was increased to $6000 \mathrm{rpm}$, and an ammonium hydroxide solution (10 vol\%) was added. After that, a black precipitate, characteristic of magnetite nanoparticles, was obtained. The precipitate was washed five times with deionized water and separated by using a magnet and then dried at $70^{\circ} \mathrm{C}$.

2.3. Preparation of MagNPs Functionalized with VTMS (MagNPs-VTMS). MagNPs were functionalized with VTMS according to the procedure reported by Davaran et al. [5]. First, VTMS (1 mL) was hydrolyzed using acetic acid $(\mathrm{pH}=4.5)$ in the presence of water and ethanol $(1: 100 \mathrm{v} / \mathrm{v})$. Then, MagNPs $(75 \mathrm{mg})$ were added to this solution and dispersed by sonication for 30 minutes. After that, the resulting solution was stirred during $72 \mathrm{~h}$ at room temperature. The

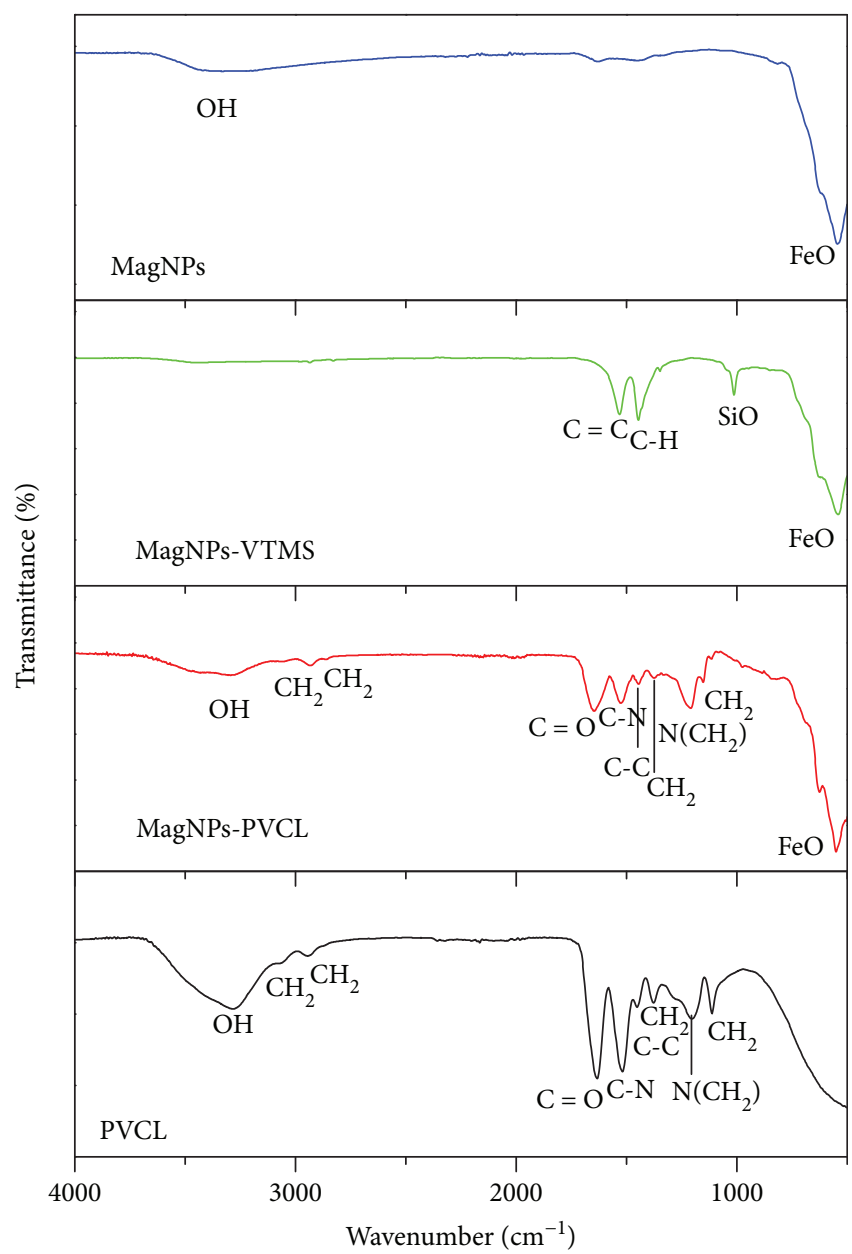

Figure 2: FT-IR spectra for MagNPs, MagNPs-VTMS, MagNPsPNVCL, and PNVCL.

VTMS-functionalized nanoparticles were collected using a magnet and washed five times with deionized water and then dried at $70^{\circ} \mathrm{C}$.

2.4. Preparation of MagNPs-PNVCL Nanocomposites. MagNPs-VTMS $(150 \mathrm{mg}$ ) were added to an aqueous solution containing $\mathrm{N}$-vinylcaprolactam and ammonium persulfate (APS) (10:1 weight ratio). The resulting solution was sonicated during 10 minutes and then degassed by bubbling $\mathrm{N}_{2}$ for 20 minutes [6]. The polymerization was carried at $60^{\circ} \mathrm{C}$ for $24 \mathrm{~h}$; after that, the MagNPs-PNVCL nanocomposite was washed several times with deionized water and collected with a magnet.

2.5. Characterization. The XRD patterns were determined by X-ray diffraction (XRD) using a Rigaku Ultima IV diffractometer with $\mathrm{CuK} \alpha$ radiation operated at $35 \mathrm{kV}$ and $25 \mathrm{~mA}$. The XRD patterns were recorded from 10 to $80^{\circ}(2 \theta)$ in $0.02^{\circ}$ steps. The morphology and size of the MagNPs were studied by high-resolution transmission electron microscopy (HRTEM) using a FEI Titan 80-300 microscope. The magnetic property measurements were carried out at room temperature using a vibrating sample magnetometer (Quantum Design) with a maximum magnetic field of $20 \mathrm{kOe}$. FTIR 


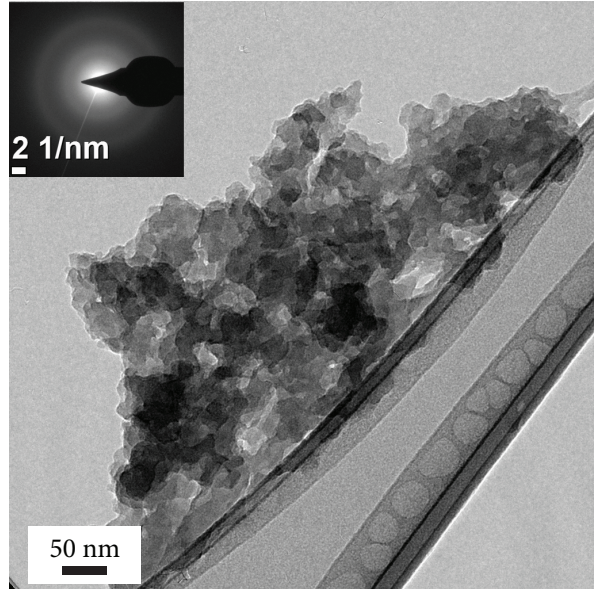

(a)

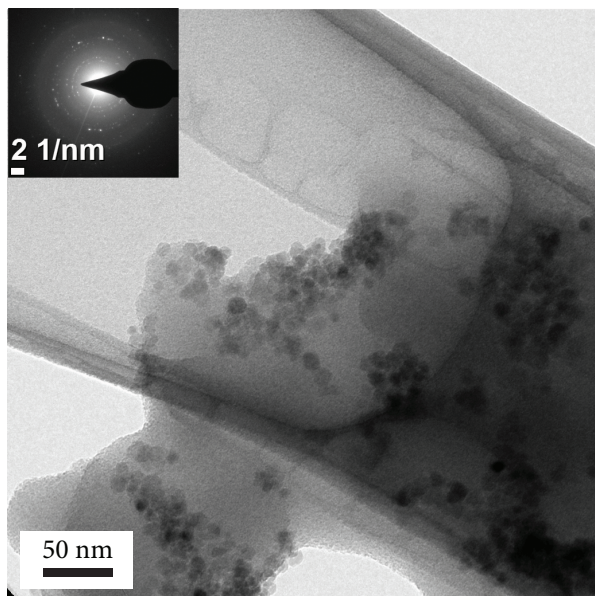

(c)

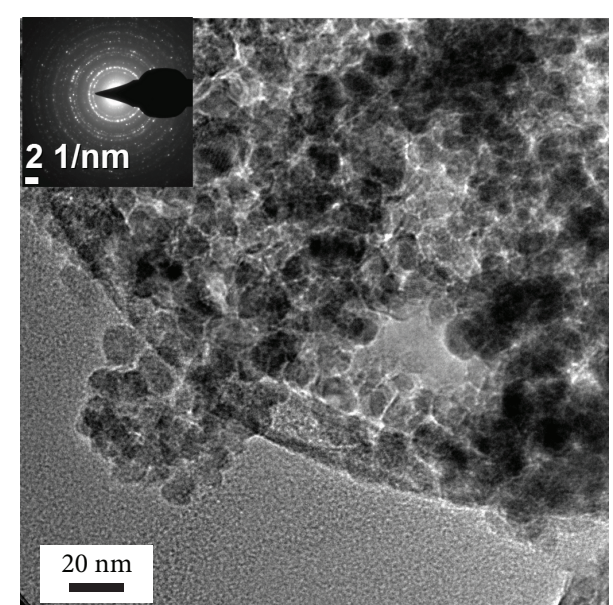

(b)

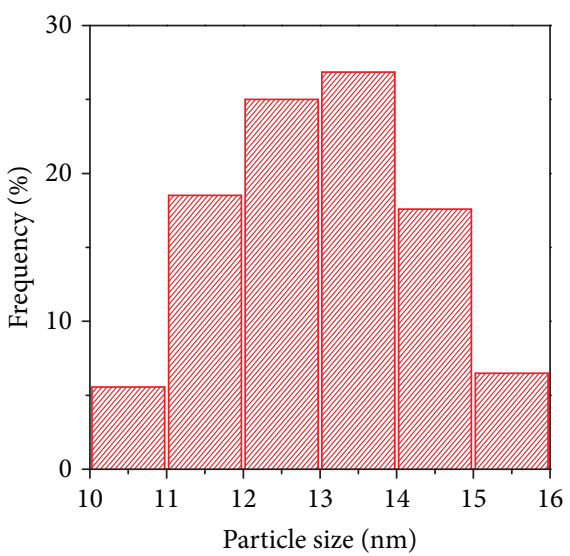

(d)

Figure 3: TEM images for PNVCL (a), MagNPs (b), and MagNPs-PNVCL nanocomposite (c) and particle size distribution of MagNPs (d).

spectra were recorded in $\mathrm{KBr}$ pellets in a Nicolet Magna-IR Spectrometer model 550. Magnetic hyperthermia heating properties were evaluated using an Ambrell heating station (EasyHeat 0224) at a frequency of $362 \mathrm{kHz}$ and $10.2 \mathrm{kA} / \mathrm{m}$ magnetic fields. The tests were performed during 10 minutes; the sample/water concentrations used were $4,6,8$, and $10 \mathrm{mg} / \mathrm{mL}$.

\section{Results and Discussion}

3.1. XRD Analysis. Figure 1 shows the $\mathrm{X}$-ray diffraction patterns for MagNPs, MagNPs-VTMS, and MagNPs-PNVCL nanocomposite. It is noted that all samples present the characteristic diffraction peaks of the magnetite according to the standard pattern (JCPDS card 19-0629). The diffraction peaks of the samples were detected at 30.3, 35.6, 43.04, $53.52,57.26,62.7$, and $74.34^{\circ}(2 \theta)$, which are assigned to the crystal planes of (200), (311), (400), (422), (511), (440), and (533), respectively. The crystalline size of the MagNPs is $10.3 \mathrm{~nm}$ using the (311) peak, estimated using Scherrer equation [7]. The samples did not show additional peaks or phases suggesting that the modified MagNPs did not suffer any structural change $[8,9]$.

3.2. FTIR Analysis. The FT-IR spectra for MagNPs, MagNPsVTMS, MagNPs-PNVCL, and PNVCL are shown in Figure 2. The MagNP spectrum shows two strong absorption bands at $543 \mathrm{~cm}^{-1}$ and $618 \mathrm{~cm}^{-1}$ due to the $\mathrm{Fe}-\mathrm{O}$ bond and a band around $3300 \mathrm{~cm}^{-1}$ corresponding to the stretching vibration $(v)$ of $\mathrm{O}-\mathrm{H}$ bond in the MagNP surface. The MagNPs-VTMS spectrum shows a band at $1017 \mathrm{~cm}^{-1}$ due to the $(v) \mathrm{Si}-\mathrm{O}$ bond from VTMS and bands at 1537, 1430, and $1325 \mathrm{~cm}^{-1}$ assigned to the $(v) \mathrm{C}=\mathrm{C}$ bond, and both are asymmetrical and symmetrical deformations $(\delta)$ of $\mathrm{CH}_{3}$, respectively [10-12]. On the other hand, the MagNPsPNVCL spectrum shows bands at 2924 and $2854 \mathrm{~cm}^{-1}$ assigned to the asymmetrical and symmetrical stretching $(v)$ of the $\mathrm{CH}_{2}$ group from PNVCL and a band at $1635 \mathrm{~cm}^{-1}$ due to the $(v) \mathrm{C}=\mathrm{O}$ bond from the amide group. Additional bands at 1524,1453 , and $1200 \mathrm{~cm}^{-1}$ assigned to the $(v) \mathrm{C}-\mathrm{N}, \mathrm{C}-\mathrm{C}$, and 

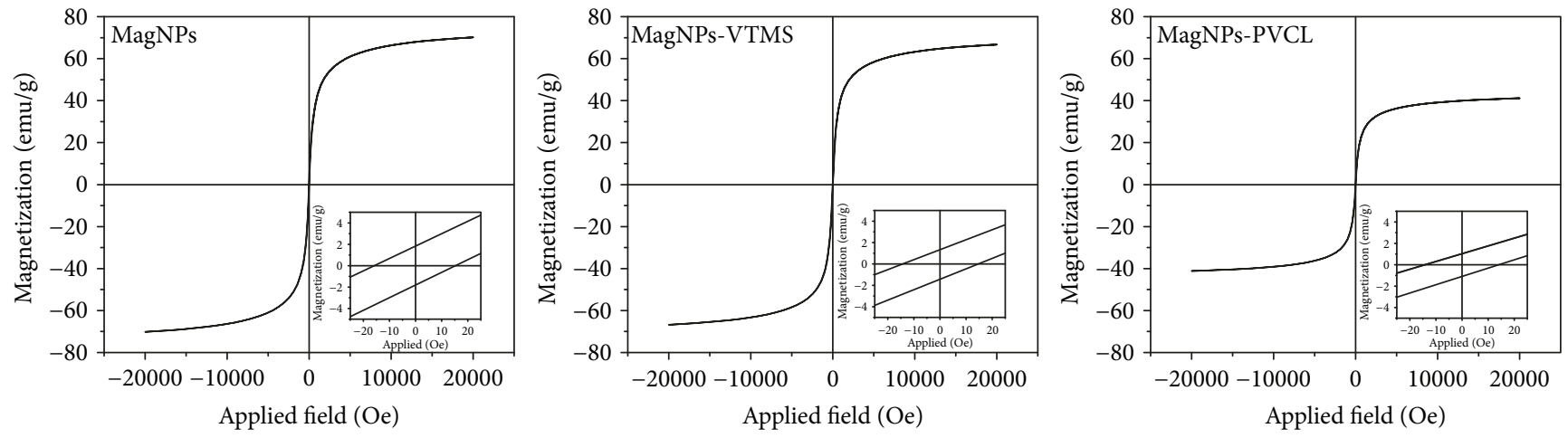

Figure 4: Hysteresis loops at room temperature for MagNPs, MagNPs-VTMS, and MagNPs-PNVCL nanocomposite.

TABLE 1: Magnetic properties of obtained materials.

\begin{tabular}{lccc}
\hline Sample & Magnetization $(\mathrm{emu} / \mathrm{g})$ & Coercivity $(\mathrm{Oe})$ & Remanence $(\mathrm{emu} / \mathrm{g})$ \\
\hline MagNPs & 70.18 & 15.9 & 1.7 \\
MagNPs-VTMS & 66.75 & 14.2 & 1.3 \\
MagNPs-PVCL & 41.13 & 14.1 & 1.1 \\
\hline
\end{tabular}
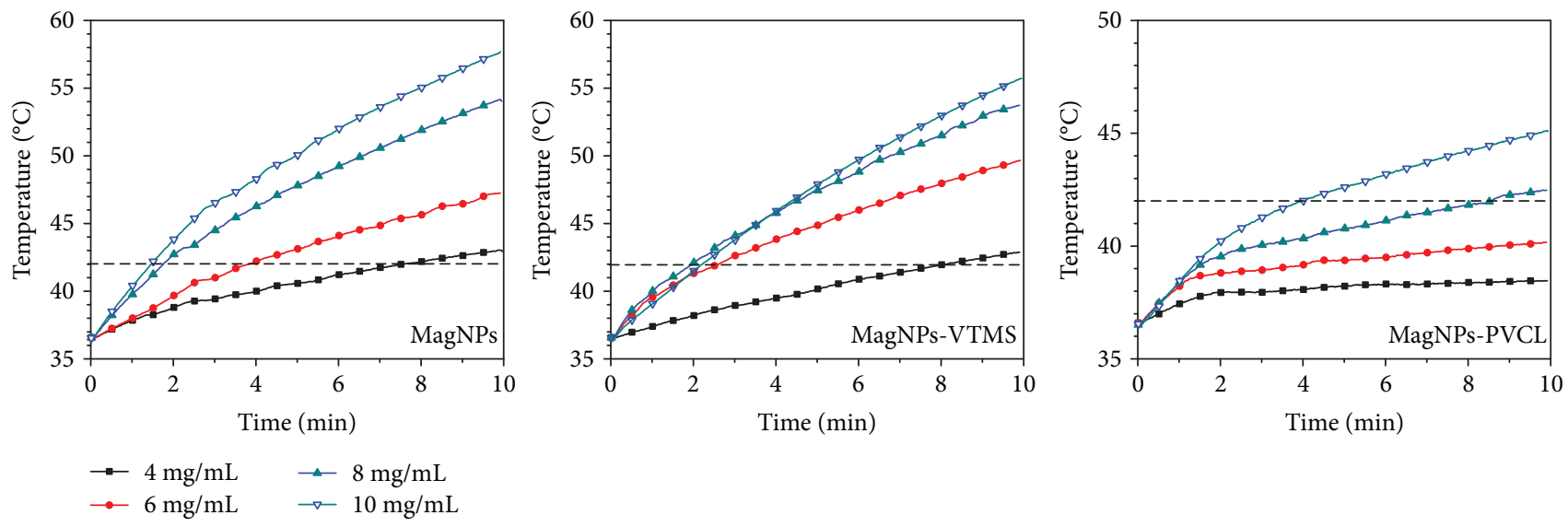

FIGURE 5: Induction heating tests for MagNPs, MagNPs-VTMS, and MagNPs-PNVCL nanocomposite.

C-N bonds from $\mathrm{N}\left(\mathrm{CH}_{2}\right)_{2}$, respectively [13]. All these bands match with those for the pristine PNVCL confirming the grafting of this polymer onto MagNPs.

3.3. TEM Analysis. TEM images of PNVCL, MagNPs, and MagNPs-PNVCL and the particle size distribution for MagNPs are shown in Figure 3. The analysis by selected area electron diffraction (SAED) for the image of PNVCL shows an amorphous material (inset in Figure 3(a)) as it was expected while the image for MagNPs reveals crystalline nanoparticles with spherical morphology (Figure 3(b)). On the other hand, Figure 3(c) shows that the MagNPs are embedded into the PNVCL matrix. The particle size for the MagNPs obtained from TEM ranges between 10 and $16 \mathrm{~nm}$ (Figure 3(d)). According to previous reports, this particle size not only allows a superparamagnetic behavior and enhanced heating capacity in magnetic induction $[14,15]$ but also is appropriated for using in drug delivery systems [16].
3.4. VSM Analysis. The magnetic properties for MagNPs, MagNPs-VTMS, and MagNPs-PNVCL were measured at room temperature and their hysteresis loops are shown in Figure 4. From this figure, it can be seen that all samples show magnetic behavior close to superparamagnetic materials with low values of coercivity $(\mathrm{Hc})$ and remanence $(\mathrm{Mr})$. Also, it can be seen that the presence of VTMS and PNVCL in the MagNP surface decreases the saturation magnetization values (Ms) causing a diminution of the MagNP magnetic moments [17, 18]. However, these values are in the range used for biomedical applications $[19,20]$. The magnetic properties of the obtained materials are shown in Table 1.

3.5. Heating Test. The induction heating test was carried out at different concentrations of MagNPs, MagNPs-VTMS, and MagNPs-PVCL (Figure 5), which are into the reported used range for biomedical applications $[21,22]$. The results show that MagNPs produced higher heating than the others even 
at low concentration $(4 \mathrm{mg} / \mathrm{mL})$. These results were expected because MagNPs are the medium from which the heat is generated, and therefore, at higher concentration of MagNPs, a higher temperature is reached. Also, it can be seen that at concentration of $10 \mathrm{mg} / \mathrm{mL}$ and magnetic induction time of 10 minutes, the MagNPs, MagNPs-VTMS, and MagNPsPNVCL reached temperatures of 58, 56, and $45^{\circ} \mathrm{C}$, respectively, suggesting that the modification with VTMS and PNVCL affects the induction heating of MagNPs. However, it is noteworthy that these temperature values are reached quickly and enough high $\left(>42^{\circ} \mathrm{C}\right)$ to cause damage or cell death with minimal damage to healthy tissues, as it has been reported previously for hyperthermia treatment [23-25]. The heat generated decreases in MagNPs-PVCL nanocomposites in comparison with MagNPs, it is important to note that the polymer in the nanocomposite provides colloidal stability of the samples and it favors the control of the temperature rise in magnetic hyperthermia. Therefore, it is possible to obtain appropriated heating values using MagNPs-PVCL nanocomposites at low magnetic induction time and low concentration in comparison with previous magnetic materials used for hyperthermia treatment $[21,23]$.

\section{Conclusions}

MagNPs-PNVCL nanocomposites were successfully prepared by free radical polymerization. The nanocomposites showed magnetic behavior close to superparamagnetic materials and can be successfully heated under a low magnetic field. Induction heating test showed that the synthesized MagNPs-PNVCL nanocomposites can reach appropriated temperatures for hyperthermia treatment in few minutes.

\section{Data Availability}

The data used to support the findings of this study are available from the corresponding author upon request (luis.garcia@ciqa.edu.mx).

\section{Conflicts of Interest}

The authors declare that they have no conflicts of interest.

\section{Acknowledgments}

Financial support for the work was provided by CONACYT through the project number 133991. A. Morfín-Gutiérrez thanks CONACYT for the financial support (scholarship 401904). The authors would like to thank E. Diaz-Barriga and G. Hurtado-López for TEM images and VSM measurements and D.A. Cortés-Hernández and L.E. de León from CINVESTAV-Unidad Saltillo for performing induction heating tests.

\section{References}

[1] A. S. Wadajkar, J. U. Menon, and K. T. Nguyen, "Polymercoated magnetic nanoparticles for cancer diagnosis and therapy," Reviews in Nanoscience and Nanotechnology, vol. 1, no. 4, pp. 284-297, 2012.
[2] M. Ma, Y. Zhang, W. Yu, H. Shen, H. Zhang, and N. Gu, "Preparation and characterization of magnetite nanoparticles coated by amino silane," Colloids and Surfaces A: Physicochemical and Engineering Aspects, vol. 212, no. 2-3, pp. 219-226, 2003.

[3] A. Gandhi, A. Paul, S. O. Sen, and K. K. Sen, "Studies on thermoresponsive polymers: phase behaviour, drug delivery and biomedical applications," Asian Journal of Pharmaceutical Sciences, vol. 10, no. 2, pp. 99-107, 2015.

[4] A. B. Salunkhe, V. M. Khot, and S. H. Pawar, "Magnetic hyperthermia with magnetic nanoparticles: a status review," Current Topics in Medicinal Chemistry, vol. 14, no. 5, pp. 572-594, 2014.

[5] S. Davaran, D. Asgari, A. Mohammad Goganian et al., "Synthesis, characterization, and in vitro evaluation of novel polymer-coated magnetic nanoparticles for controlled delivery of doxorubicin," Nanotechnology, Science and Applications, vol. 5, pp. 13-25, 2012.

[6] M. Rahimi, A. Wadajkar, K. Subramanian et al., "In vitro evaluation of novel polymer-coated magnetic nanoparticles for controlled drug delivery," Nanomedicine: Nanotechnology, Biology and Medicine, vol. 6, no. 5, pp. 672-680, 2010.

[7] B. D. Cullity and S. R. Stock, Elements of X-Ray Diffraction, Prentice Hall, New York, USA, 3rd edition, 2001.

[8] Y. Osuna, K. M. Gregorio-Jauregui, J. Gerardo Gaona-Lozano et al., "Chitosan-coated magnetic nanoparticles with low chitosan content prepared in one-step," Journal of Nanomaterials, vol. 2012, Article ID 327562, 7 pages, 2012.

[9] M. El Zowalaty, T. J. Webster, M. Z. Hussein, M. Ismail, and S. Hussein-Al-Ali, "Synthesis, characterization, controlled release, and antibacterial studies of a novel streptomycin chitosan magnetic nanoantibiotic," International Journal of Nanomedicine, vol. 9, pp. 549-557, 2014.

[10] R. A. Bini, R. F. C. Marques, F. J. Santos, J. A. Chaker, and M. Jafelicci Jr, "Synthesis and functionalization of magnetite nanoparticles with different amino-functional alkoxysilanes," Journal of Magnetism and Magnetic Materials, vol. 324, no. 4, pp. 534-539, 2012.

[11] M. Yamaura, R. L. Camilo, L. C. Sampaio, M. A. Macêdo, M. Nakamura, and H. E. Toma, "Preparation and characterization of (3-aminopropyl) triethoxysilane-coated magnetite nanoparticles," Journal of Magnetism and Magnetic Materials, vol. 279, no. 2-3, pp. 210-217, 2004.

[12] K. Can, M. Ozmen, and M. Ersoz, "Immobilization of albumin on aminosilane modified superparamagnetic magnetite nanoparticles and its characterization," Colloids and Surfaces B: Biointerfaces, vol. 71, no. 1, pp. 154-159, 2009.

[13] T. Kavitha, I.-K. Kang, and S.-Y. Park, "Poly(N-vinyl caprolactam) grown on nanographene oxide as an effective nanocargo for drug delivery," Colloids and Surfaces B: Biointerfaces, vol. 115, pp. 37-45, 2014.

[14] H. Gavilán, O. Posth, L. K. Bogart, U. Steinhoff, L. Gutiérrez, and M. P. Morales, "How shape and internal structure affect the magnetic properties of anisometric magnetite nanoparticles," Acta Materialia, vol. 125, pp. 416-424, 2017.

[15] I. Obaidat, B. Issa, and Y. Haik, "Magnetic properties of magnetic nanoparticles for efficient hyperthermia," Nanomaterials, vol. 5, no. 1, pp. 63-89, 2015.

[16] Q. Zhang, X. Wang, P.-Z. Li et al., "Biocompatible, uniform, and redispersible mesoporous silica nanoparticles for cancer- 
targeted drug delivery in vivo," Advanced Functional Materials, vol. 24, no. 17, pp. 2450-2461, 2014.

[17] K. Petcharoen and A. Sirivat, "Synthesis and characterization of magnetite nanoparticles via the chemical co-precipitation method," Materials Science and Engineering B, vol. 177, no. 5, pp. 421-427, 2012.

[18] R. López, M. Pineda, G. Hurtado et al., "Chitosan-coated magnetic nanoparticles prepared in one step by reverse microemulsion precipitation," International Journal of Molecular Sciences, vol. 14, no. 10, pp. 19636-19650, 2013.

[19] A. Mukhopadhyay, N. Joshi, K. Chattopadhyay, and G. De, “A facile synthesis of PEG-coated magnetite $\left(\mathrm{Fe}_{3} \mathrm{O}_{4}\right)$ nanoparticles and their prevention of the reduction of cytochrome $\mathrm{C}$," ACS Applied Materials and Interfaces, vol. 4, no. 1, pp. 142149, 2012.

[20] S. Rani and G. D. Varma, "Superparamagnetism and metamagnetic transition in $\mathrm{Fe}_{3} \mathrm{O}_{4}$ nanoparticles synthesized via coprecipitation method at different $\mathrm{pH}$," Physica B: Condensed Matter, vol. 472, pp. 66-77, 2015.

[21] E. M. Múzquiz-Ramos, V. Guerrero-Chávez, B. I. MacíasMartínez, C. M. López-Badillo, and L. A. García-Cerda, "Synthesis and characterization of maghemite nanoparticles for hyperthermia applications," Ceramics International, vol. 41, no. 1, pp. 397-402, 2015.

[22] Q. A. Pankhurst, J. Connolly, S. K. Jones, and J. Dobson, "Applications of magnetic nanoparticles in biomedicine," Journal of Physics D: Applied Physics, vol. 36, pp. 167-181, 2003.

[23] J. C. Ríos-Hurtado, A. C. Martínez-Valdés, J. R. RangelMéndez, J. C. Ballesteros-Pacheco, and E. M. MúzquizRamos, "Facile synthesis and characterization of $\mathrm{Mn}_{\mathrm{x}} \mathrm{Zn}_{1-\mathrm{x}} \mathrm{Fe}_{2} \mathrm{O}_{4} /$ activated carbon composites for biomedical applications," Journal of Ceramic Science and Technology, vol. 7, no. 3, pp. 289-294, 2016.

[24] Z. Hedayatnasab, F. Abnisa, and W. M. A. W. Daud, "Review on magnetic nanoparticles for magnetic nanofluid hyperthermia application," Materials and Design, vol. 123, pp. 174196, 2017.

[25] M. Bañobre-López, A. Teijeiro, and J. Rivas, "Magnetic nanoparticle-based hyperthermia for cancer treatment," Reports of Practical Oncology \& Radiotherapy, vol. 18, no. 6, pp. 397-400, 2013. 


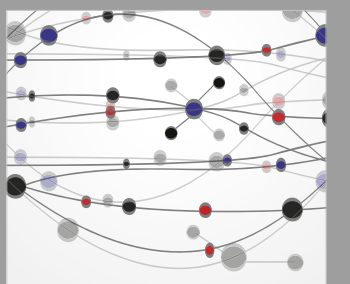

The Scientific World Journal
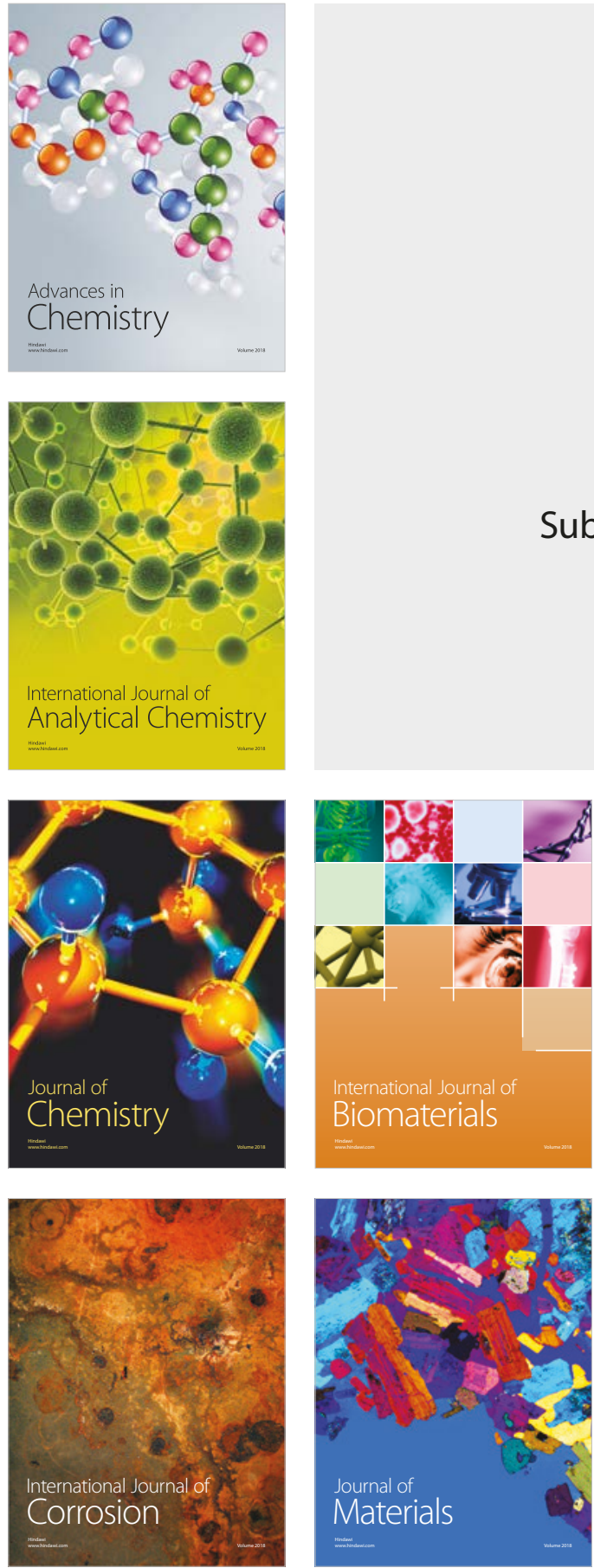

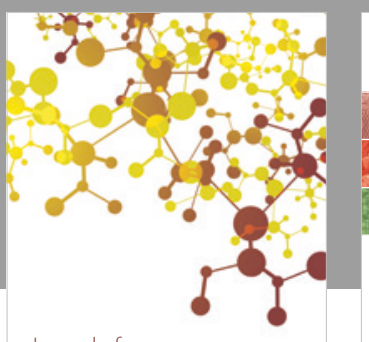

Journal of

Applied Chemistry
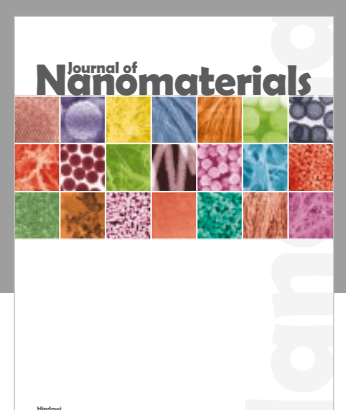

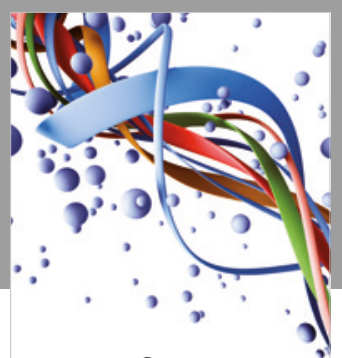

Scientifica

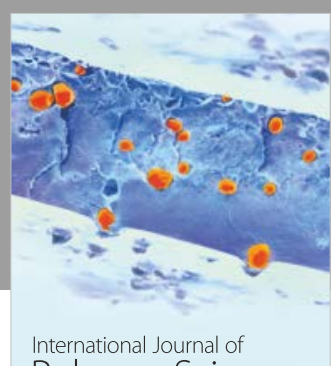

Polymer Science

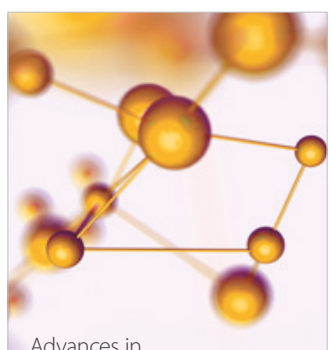

Physical Chemistry
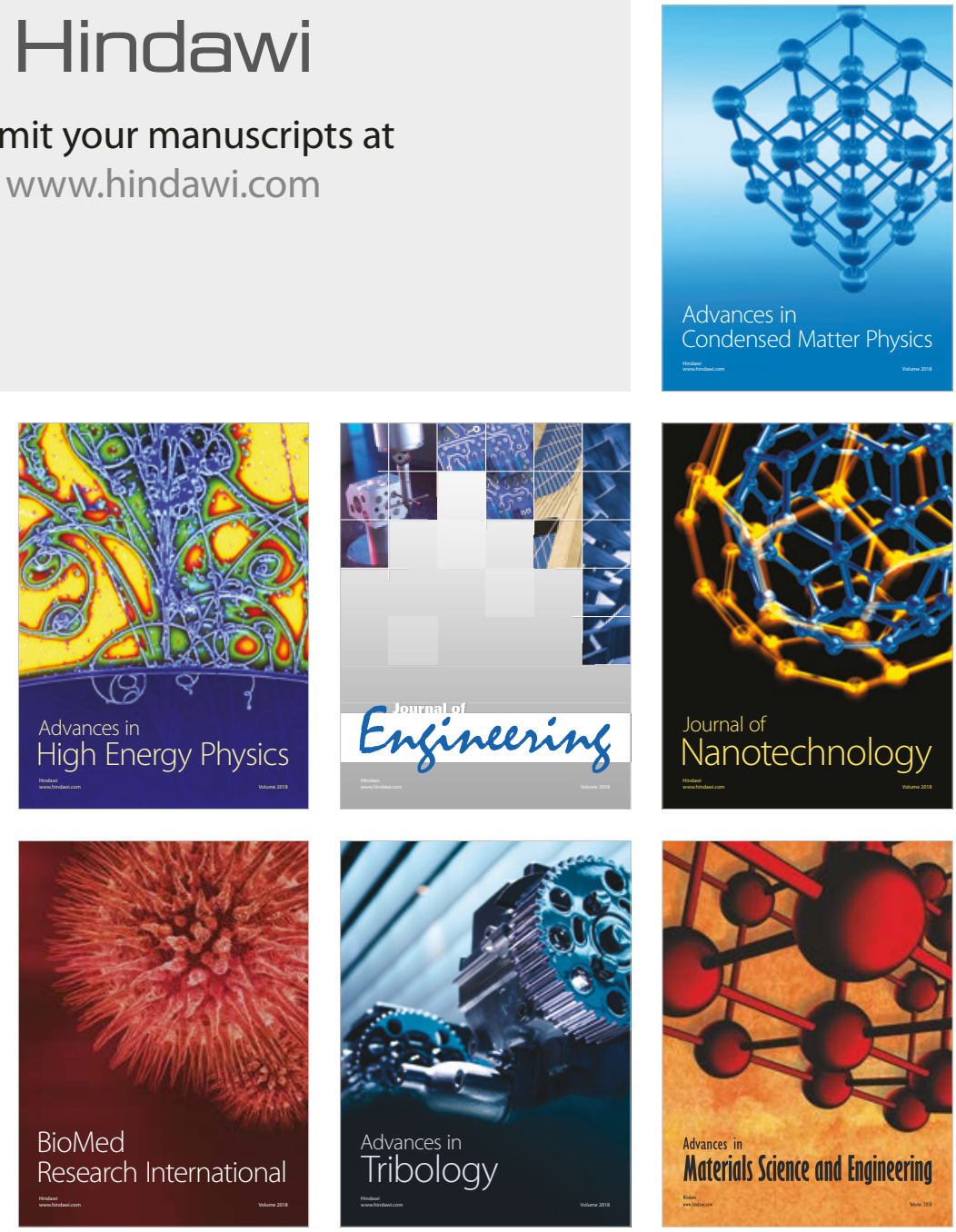